\title{
ENTREVISTA COM ANA MAFALDA LEITE
}

Flavio García

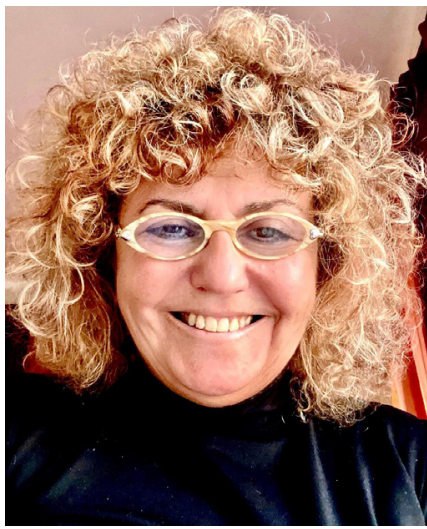

Ana Mafalda Leite inicia o seu percurso poético em 1984 com o livro Em Sombra Acesa. Nasceu em Portugal, mas cresceu no norte de Moçambique e fez os primeiros estudos universitários na Universidade Eduardo Mondlane, em Maputo, Moçambique. Licenciou-se em Filologia Românica na Faculdade de Letras de Lisboa, Portugal, onde é Professora Associada, especialista em Literaturas Africanas. É ensaísta, docente e principalmente poeta.

Como ensaísta o seu percurso inclui várias obras (que têm sido reeditadas pelo seu interesse) que problematizam as literaturas africanas nas suas vertentes teóricocríticas, nomeadamente a problematização de géneros (A Modalização Épica nas Literaturas Africanas, 1991), a 
relação entre oralidade e escrita (Oralidades \& Escritas nas Literaturas Africanas 1998-2014), a integração na área dos estudos pós-coloniais (Literaturas Africanas e Formulações Pós-Coloniais 2003-2014), sempre com uma especial atenção para a literatura moçambicana, à qual dedicou um estudo sobre a obra do poeta José Craveirinha (1990). É coautora e organizadora de um dos primeiros livros sobre a história das literaturas africanas de língua inglesa: The Postcolonial Literature of Lusophone Africa (1990). Tem contribuído com a sua obra para uma importante divulgação crítica das literaturas africanas e desenvolvido atividade docente como professora convidada em várias universidades africanas, brasileiras, americanas e europeias.

Janela para o Índico (2020) é uma antologia de poesia, que mostra um percurso de trinta e cinco anos de poesia da autora (9 livros), e a metáfora da janela enuncia essa abertura à viagem e assinala a sua movência cultural entre Moçambique e Portugal, ou vice-versa, em trânsito de inspiração e prática poética. Ana Mafalda Leite, entre outros temas como a relação da poesia com a pintura e com a música, reflete, na sua poesia, sobre conceitos de identidade, pertencimento e partilha culturais, numa constante viagem interior do sujeito. Abrindo-se a uma interxtextualidade 
múltipla, oriunda da poesia oriental, da lírica portuguesa, da poesia índica e africana, a sua escrita reconfigura de forma única e original múltiplas origens citacionais.

Em 2015, Ana Mafalda Leite recebeu o prémio Femina de Literatura; em 2019, o Prémio Afrolic.

Vamos ao diálogo.

P.: Ser mulher, professora, pesquisadora, teórica, crítica e poeta tem um peso diferenciado em relação ao ser homem, professor, pesquisador, teórico, crítico e poeta?

R.: A experiência de género fundamenta uma experiência de vida. Mas confesso que nunca senti verdadeiramente uma cisão entre os dois mundos no quadro profissional. Há muitos escritores que eu amo, que fizeram parte da minha formação, independentemente do género. Minha percepção do mundo criativo é humana e multiforme e procura harmonizar e entender diferenças. Por exemplo, no meu livro O Amor essa forma de Desconhecimento (2010) há um conjunto de poemas que dramatiza as duas vozes (uma feminina e outra masculina), visões do amor. Como estudiosa, nos últimos anos, tenho procurado estar mais atenta à literatura produzida por mulheres, tendo em conta os contextos actuais de recuperação dos arquivos 
femininos e de enquadramento paritário de género em todas as áreas, inclusive a literária.

P.: O que se deu primeiro, ser poeta ou professora, pesquisadora, teórica, crítica?

R.: Eu nasci poeta, se posso formular assim. É o gosto pela literatura e pelas artes que me leva a optar por fazer um curso de Letras, opção, aliás, que na altura balançou entre cinema, belas-artes e filosofia. Na época não havia escolas de cinema. Mais tarde, já em Lisboa, torneime frequentadora assídua da cinemateca e dos poucos festivais de cinema que existiam. Ser escultora ou pintora, pensei ser também um rumo, no fundo. As apetências eram já nessa fase juvenil entre a criação e a meditação sobre ela.

P.: Em que medida ser professora, pesquisadora, teórica, crítica interfere no ser poeta?

R.: É bastante útil, porque permite o balanço entre fazer e observar, que agudiza a consciência da escrita como artefacto. Quando escrevo, no entanto, não lembro essa sedimentação de leitura anterior. São processos aparentemente independentes. A poesia surge fora do contexto analítico. É iluminação. Na maioria das vezes, nasce de um silêncio profundo, que começa a ganhar 
voz e traz consigo escolhas e fragmentos de vivências, de sentidos, de restos sensíveis da memória. Fazer um livro é talvez articular num cenário a iluminação que vai ganhando vocalidades.

P.: Em que medida ser poeta interfere no ser professora, pesquisadora, teórica, crítica?

R.: Às vezes interfere no sentido de nem sempre poder estar a ler as obras e autores que gostaria. Para aprofundar uma área teórica e crítica tenho de ocupar um tempo de leitura que poderia ser dedicado a outros livros e à poesia. Fico com a sensação de alguma perda e da impossibilidade de equilíbrios necessários.

P.: Se pudesse ou tivesse que optar entre ser professora, pesquisadora, teórica, crítica ou poeta, que opção faria? Por quê?

R.: Seria poeta a tempo inteiro, embora gostasse de ler criticamente. Há um grande poeta que muito admiro, Octavio Paz, que representa para mim um grau de excelência entre a criatividade e o sentido crítico. Todos os seus livros são criativos, sendo críticos. Como é o caso de A Chama Dupla, O Arco e a Lira, apenas para citar dois magníficos exemplos. 
P.: Nasceu em Portugal, mas cresceu em Moçambique. Como convive com esses dois diferentes imaginários de identidade nacional tanto em sua prática profissional como professora, pesquisadora, teórica, crítica, quanto em sua experiência artística como poeta?

R.: Eu nasci em Portugal, de facto, mas cheguei a Moçambique com um ano de idade. É como se nascesse de novo aí. Eu tematizo esta questão em vários poemas e livros, nomeadamente em Passaporte do Coração (2001), Livro das Encantações (2005) Outras Fronteiras (2017). Na prática a minha terra, onde cresço, é Moçambique até aos vinte anos. Depois vim para Portugal completar o curso superior, e quando cheguei, para mim era um país bastante estrangeiro, se é que posso dizer assim. Mas abriu-me outras paisagens, interesses culturais, para a Europa e resto do mundo e para outras percepções artísticas. Ainda hoje, passados muitos anos, me sinto em casa quando volto a Moçambique, e em Portugal, naturalmente estabeleci laços e estou também em casa, embora a minha opção por me dedicar às literaturas africanas, tenha sido uma por um lado uma opção afectiva, forma de não me desligar das minhas referências de matriz, a sul e oriente, e por outro lado de conhecer as culturas desse espaço que me formou. Há uma íntima 
relação de afectos, paixões e curiosidades necessárias, na escolha de aprofundamento de conhecimento do meu campo de trabalho investigativo e no quadro das minhas referências literárias e culturais. Perceber o chão, a história, os contextos, das minhas pertenças, das minhas partilhas. É pela poesia e pela literatura que eu estou em casa. Ou de outra forma, nelas encontro a minha morada múltipla.

P.: O que fala mais alto na visão da pesquisadora, teórica e crítica, o sentimento de ser Portugal ou Moçambique? R.: Apesar de se ter tornado hoje politicamente correcto, enunciar um único lugar de fala, eu falo necessariamente a partir de dois lugares, que se entrecruzaram e me dão a possibilidade de perceber muitas questões de forma diferenciada. Por um lado com a minha experiência vivencial africana, de estudiosa de Moçambique, e foi aí que iniciei a Universidade, onde me respeitam muito, apreciam e utilizam o meu trabalho teórico-crítico, e por outro como estudiosa de uma universidade portuguesa, que estabelece uma observação necessariamente crítica no quadro das questões ligadas à "Iusofonia".

P.: O que fala mais alto na criação da poeta, o sentimento de ser Portugal ou Moçambique? 
R.: Bom, eu sou um caso de escritor que surge no processo histórico de transição da colónia para a póscolónia. Digamos que começo a escrever mais ou menos em simultâneo à primeira geração pós-colonial moçambicana, que é a geração da Charrua. Eu publico meu primeiro livro em 1984, mas em Portugal. No entanto, toda a minha formação foi, desde tenra idade, em Moçambique, e culturalmente me identifico por Moçambique, cultural e literariamente. Mas não posso, até por razões da ordem de nascimento e de passaporte civil, negar a minha ascendência portuguesa. E honestamente para não dizerem que faço um uso indevido duma pertença, eu julgo-me pertencente a duas culturas, e a dois países, de certa maneira. Um em que eu nasci, e outro em que cresci, que me formou, que é Moçambique. A literatura com que eu me identifico e na qual eu me situo afetiva e literariamente, e em termo de testemunho de passagem, é a moçambicana. Mas com a postura de uma abertura muito grande; um dos temas que eu trabalho é o tema da identidade, ou seja, destas pertenças múltiplas, e desses espaços que vão para além do espaço telúrico e que passam também pelo espaço da língua. Porque é através de uma língua que eu no fundo partilho diferentes literaturas. Eu gostaria de 
pertencer às duas literaturas, mas a academia é pouco sensível a esse tipo de partilhas. Há alguns casos bem interessantes de escritores reivindicados por diferentes espaços literários, como por exemplo o caso de Doris Lessing, que nasceu na Pérsia, de família inglesa, e foi criança para o Zimbabwe, onde cresceu, e é uma escritora que pertence aos dois mundos de língua inglesa. Outro possível exemplo, pesem-se as diferenças, é o de Salman Rushdie, enfim podemos dizer que hoje são inúmeras as duplas pertenças em termos criativos.

P.: Como valora sua produção acadêmica em relação à cultura e à arte africana ou, se preferir, moçambicana mais especificamente?

R.: Para mim, escrever sobre literaturas africanas, reflectir sobre estes campos literários foi uma forma de contribuir para o meu auto-conhecimento e simultaneamente considerei sempre essa atividade como uma contribuição para o desenvolvimento do estudo crítico sobre a área das literaturas africanas, uma vez que o meu trabalho é seminal na área, conjuntamente com o de alguns colegas. Por outro lado é para mim muito importante que essa mais valia crítica seja uma referência, significa que o meu trabalho foi de algum modo importante. Tenho vários livros de ensaios publicados 
em Moçambique e também no Brasil, além de Portugal, e fico feliz por ter feito uma primeira tese de mestrado sobre a obra do poeta José Craveirinha, posteriormente publicada em livro, A Poética de José Craveirinha (1990).

P.: De uns anos para cá, sem abandonar os estudos de literatura, migrou para os de cinema. Qual a situação atual do cinema na África ou, se preferir, em Moçambique mais especificamente?

R.: Não migrei, fui entendendo a importância do cinema africano, sua relação com a literatura e abri o quadro da arte narrativa também para o cinema, que é muito importante em África, e em Moçambique tem uma história significativa com realizadores internacionalizados. Nomeadamente o cinema permite uma articulação com a oralidade e com as línguas nacionais, capaz de alargar públicos e permitir uma pedagogia crítica da sociedade e da história. Publiquei em co-autoria com Carmen Tindó Secco e Luís Carlos Patraquim um livro intitulado Cinegrafias Moçambicanas (Kapulana) e tenho em preparação outro com a colega Maria Geralda Miranda sobre cinema africano. Este interesse sobre a narrativa visual surge também no quadro de um Projecto que coordenei, intitulado Narrativas Escritas e Visuais da 
Nação Pós-colonial (CESA-FCT) que procurou evidenciar as marcas transnacionais deste tipo de narrativa e que resultou em dois livros : Nação e Narrativa PósColonial III - Literatura \& Cinema - Cabo Verde, Guiné-Bissau e São Tomé e Príncipe -Ensaiose Nação e Narrativa PósColonial IV - Literatura \& Cinema - Cabo Verde, Guiné-Bissau e São Tomé e Príncipe - Entrevistas.( Lisboa: Edições Colibri, 2018.).

P.: Como anda a produção literária africana neste momento?

R.: Assiste-se a um momento importante de renovação em todo o continente africanos e nas suas diásporas. Naturalmente depende de cada país, mas posso dizer que, por exemplo, em Moçambique multiplicam-se não só as editoras e os autores, em número crescente e surgem obras em diferentes géneros, poesia, romance, conto, conto infantil, policial, ficção científica, etc. Em Angola o ritmo editorial também é grande, de uma forma geral observa-se o surgimento nas novas gerações de propostas diferentes, que discutem e questionam as crises e a história dos seus países. Há ainda uma tendência de abertura ao mundo e de diálogo criativos nos vários países africanos de língua portuguesa. 
P.: Qual o lugar da literatura moçambicana no universo da literatura africana atual?

R.: A literatura moçambicana tem um dos mais importantes escritores de língua portuguesa, já quase um autor global, Mia Couto, além de figuras tão importantes como Paulina Chiziane, João Paulo Borges Coelho, Ungulani Ba Ka Khosa, Adelino Timóteo, apenas para citar alguns autores. No domínio da poesia há excelentes poetas, uma tradição, que se mantém na literatura moçambicana, e a literatura infanto-juvenil encontra-se em franco desenvolvimento. As mais novas gerações trazem excelentes propostas editoriais. Vive-se um momento alto no quadro da literatura moçambicana.

P.: Há um lugar necessário e próprio de fala, que seja distinto e diferenciado, da teorização da crítica da arte africana, especialmente da literatura e cinema? Por quê?

R.: O lugar de fala pode localizar teoricamente quem está escrevendo ou falando, em qualquer área do saber, para fundamentar a enunciação. Em resultado da produção colonial sobre África, em que os africanos não eram os sujeitos produtores do conhecimento, mas sim objeto, e quem diz África, diz a Índia ou outras áreas coloniais, hoje procura-se defender a produção do 
conhecimento localmente. Por exemplo, a obra seminal de Edward Said Orientalismo é um exemplo que nos mostra como a produção do saber sobre o Oriente foi fabricada pelo Ocidente. No fundo trata-se de tentar "descolonizar" áreas do saber, neste caso, respeitantes às antigas culturas colonizadas, como, por exemplo, as africanas e afrodescendentes. No entanto, o exercício do lugar de fala, extremado, também pode criar estranhas ambiguidades ideológicas, medos e fobias raciais, ensimesmamentos problemáticos e paternalismos pouco criativos.

\section{P.: Como Ana Mafalda Leite se vê no universo da teoria e crítica da arte africana?}

R.: Uma leitora muito curiosa, reflexiva, sempre procurando ter a postura crítica e estética de uma observadora/participante. Sinto a necessidade de conhecer os rumos das teorias e das tendências de desenvolvimento artístico, para entender melhor as diferentes culturas e sociedades, e o que se passa lá, na terra, nos diferentes espaços culturais de um continente.

P.: Como Ana Mafalda Leite se vê no universo da literatura africana, tendo-se por poeta?

R.: Em casa. Ou abrindo a Janela para o Índico. 
P.: Janela para o Índico - poesia incompleta (1984 -2019), lançado em 2020, reúne "toda" a sua poesia publicada até o ano de 2019?

R.: Janela para o Índico reúne uma escolha de poemas que eu fiz dos vários livros que publiquei até 2019. Cada livro tem a sua singularidade e existe com outros poemas que nesta antologia não estão inteiramente contemplados.

P.: O subtítulo "poesia incompleta (1984 -2019)" é um índice de que algo novo já está por vir?

R.: Enquanto for viva, espero continuar a escrever, o volume de poesia Janela para Oriente é incompleto porque não reúne todos os poemas publicados e também porque não integra aqueles ainda por escrever, porque espero ainda fazer mais algum(ns) livro(s).

P.: O volume Janela para o Índico - poesia incompleta (1984 - 2019) traz, ao seu final, fragmentos de diferentes paratextos, assinados por variados críticos, em relação aos livros em que, originariamente, as poesias que o integram foram publicadas. Muitos dos autores desses paratextos são figuras de incontestável importância em Moçambique, Portugal ou Brasil. Diria que se trata de uma prevenção à crítica adiante, de uma autodefesa prévia ou de uma estratégia meramente mercadológica? 
R.: Como sou uma poeta lenta e bissexta, e o actual panorama de edição é de uma enorme velocidade e multiplicidade, quis fazer uma espécie de amostra do historial de alguma da fortuna crítica sobre a minha poesia, reunida na Janela para Oriente, que perfaz 35 anos de publicação poética, ou seja dar a conhecer alguma da crítica que percorre vários momentos de diferentes momentos de publicação. A memória é muito curta nos tempos em que vivemos, e o meu intuito foi mostrar um percurso, e a recepção que houve de algumas dessas obras. Por outro lado como fui publicando ora em Moçambique, e também no Brasil e já não editava em Portugal desde 2005, achei necessário ao editar esta antologia relembrar os diferentes momentos críticos da recepção, oriundos dos espaços literários que a minha poesia percorreu. No fundo, as pessoas conhecem muito mais a minha produção ensaística do que a poética, e senti necessidade de reavivar não só a poesia, mas também uma memória crítica sobre o meu percurso criativo.

P.: De uma maneira geral, a primeira metade desse livro, que corresponde à primeira fase de sua produção, é majoritariamente, senão que exclusivamente, lírica; a segunda metade, contudo, imiscui o lírico e narrativo, 
opondo, aqui, sem retomar a poética aristotélica, duas vertentes de poesia. O poema que é reproduzido na contracapa, "Tenho o nome de um barco", aproxima da estrutura épico-narrativa. Como se deu, em sua opinião, essa mudança em seu fazer poético?

R.: "Tenho o nome de um barco" é um poema autobiográfico que conta a minha história pessoal. Senti necessidade de o escrever para responder a questões sobre a minha dúplice origem. Essa narratividade foi surgindo naturalmente e fruto dos temas a desenvolver; poderei também dizer que a leitura e o exercício critico sobre a narrativa, e em especial sobre a poesia africana, contribuíram para esse mesclar entre lírica e narrativa, e também outras leituras da poesia de vários orientes. Por outro lado, na fase inicial, a lírica que desperta Em Sombra Acesa (1984), ainda procura a voz e os espaços, questiona-se e faz desse processo poesia. Mais adiante essa(s) voz(es) começa(m) a narrar, a contar episódios, reflexões, memórias, veja-se por exemplo o que acontece nos poemas de O Livro das Encantações (2005). Houve também um forte desejo de escrita narrativa, eu tive em mente escrever um romance e não o cheguei a fazer. Foi o que aconteceu com o último livro, Outras Fronteiras, 
Fragmentos de Narrativas (2017), que nasce desse projecto de trabalho. Acabei por converter um projecto de ficção em poesia. Percebi, tendo em conta a minha predilecção pela poesia, a minha fragmentária memória, que ao escrever poemas poderia integrar fragmentos de narrativa, podia ser uma opção esteticamente inovadora.

P.: Que Ana Mafalda se aposenta (no sentido que o verbo é utilizado no Brasil) primeiro, a acadêmica ou a poeta? Por quê?

R.: Naturalmente só se aposentará a académica, embora pense continuar a fazer pesquisa. Gosto muito e é sempre provocador intelectualmente. Agora a poeta nunca se irá aposentar, porque é a minha mais grata atividade lúdica e para mim é muito libertador e energeticamente importante escrever poemas, construir alternativas criadoras à realidade e quotidiano, reflectir sobre o nosso tempo (interior e exterior, passado e presente), enfim dar voz às vozes que me procuram.

P.: Se fosse destacar uma escrita acadêmica de sua trajetória, qual seria? Por quê?

R.: A publicação de A Poética de José Craveirinha, fruto da minha tese de Mestrado, que me abriu as portas para as questões relativas às importantes questões do interface 
oralidade e escrita nas literaturas africanas. Depois as teorias sobre o Pós-colonialismo. Mais recentemente os Estudos sobre o Oceano Índico.

P.: Se fosse destacar um livro de poesia de sua trajetória, qual seria? Por quê?

R.: Rosas da China (1999) foi muito importante, uma espécie de "inebriamento" de escrita, em que múltiplas vozes me assaltavam, como ópios. Teve por base uma música de fundo, Carmina Burana, e o espectáculo coreográfico das emoções. Foi um exercício de enorme prazer a escrita desse livro e o estado de encantamento em que ele me envolvia. A componente narrativa e dramática também começa aí.

P.: Qual de suas poesias mais vive em suas memórias? Por quê?

R.: O livro Outras Fronteiras, Fragmentos de Narrativas (2017), porque recorre aos espaços da infância e da memória. Situa-se uma parte no Norte de Moçambique, em Moatize, onde cresci.

P.: O que diria para uma mulher que esteja começando a vida como professora, pesquisadora, teórica, crítica?

R.: Alimente-se da curiosidade de ler sem limites, da arte e da crítica, experimente tudo, teatro, cinema, literatura, 
arte, dança. Deixe-se encantar e depois pergunte o que a encantou.

P.: O que diria para uma mulher que esteja começando a vida como poeta?

R.: Que viva de todas as maneiras possíveis, viaje muito, experimente as diferenças, partilhe afectos, e sonhe alto. E leia muita poesia.

P.: Incomoda-lhe o dual e o neutro serem marcados pelo masculino na língua portuguesa?

R.: Não. Isto porque me parece que não é a língua em que se escreve que determina a abertura a questões de género, mas sim o que trata essa língua, ou o que se faz com ela.

P.: Recentemente, a despeito das críticas que se fazem, textos destinados ou referidos aos dois gêneros aparecem com um " $x$ " no lugar do artigo "o", notadamente nos media digitais. Como vê isso?

R.: Questões da nossa época. Não me pronuncio sobre códigos, nem acordos ortográficos ou digitais.

P.: Por que "poeta" e não "poetisa"? Lembre-se de que Dilma Rousseff, no Brasil, se identificou como "presidenta" e não "presidente".

R.: Eu curiosamente gosto da palavra poetisa, embora poeta por terminar com "a" seja uma designação bastante 
feminina. Ser poeta é ser todos os géneros. Gosto de ser uma poeta que se poetiza, ou uma poetisa que se poeta. Poetemos, se poeta ou poetisa, o poema é que nos interessa verdadeiramente.

\section{P.: O que gostaria de ter respondido e não perguntamos?}

R.: Agradeço muitíssimo a generosidade das suas perguntas, e espero através das respostas levar alguns estudantes e curiosos a conhecerem mais a minha poesia e produção ensaística.

\section{P.: Qual a mensagem que deixa aos leitores dessa entrevista?}

R.: Gostaria que lessem a minha poesia e se aventurassem em algumas das minhas viagens em diferentes espaços literários. Que se deixassem encantar, que os poemas fizessem nascer a vocalidade performativa e saíssem dos silêncios da página para um espaço mais performático. Que ganhassem vida. Que a Janela para o Índico faça surgir paisagens inesperadas e liberte outras vozes.

Flavio García

Pós-doutor na área de Culturas e Literaturas Africanas de Língua Portuguesa da Faculdade de Letras da Universidade de Lisboa (2021), na área de Teoria da Literatura, na Faculdade de Letras da Universidade de Coimbra (2016), na área de Estudos da Literatura do PPGLetras da UFRGS (2012), e na área de Poética do PPG em Ciência da Literatura da UFRJ (2008); doutor em Letras pela PUC-Rio (1999). 
Professor titular da Universidade do Estado do Rio de Janeiro - UERJ; bolsista PROCIÊNCIA (UERJ-FAPERJ).

Líder do Grupo de Pesquisa/CNPq "Nós do Insólito: vertentes da ficção, da teoria e da crítica"; pesquisador dos Grupos de Pesquisa "Vertentes do Fantástico na literatura" e " A narrativa ficcional para crianças e jovens: teorias e práticas"; membro fundador do GT ANPOLL "Vertentes do Insólito Ficcional";integra a equipe de pesquisadores do CLP da Faculdade de Letras da Universidade de Coimbra e do GEF da Universidad Autónoma de Barcelona.

http://lattes.cnpq.br/4242057381476599

https://orcid.org/0000-0003-0761-8092

flavgarc@gmail.com 